\title{
Magnitude, clinical spectrum and etiology of hepatobiliary disorders in children- a tertiary care experience
}

\author{
Maheswari $K^{1}$, Shanmuga Arumugasamy $S^{2}$, Manikandasamy $V^{3}$, Shafna azeez ${ }^{4}$, Hemalathaa $K^{5}$ \\ ${ }^{1}$ Dr. Maheswari K, Assistant Professor, Department of Paediatrics, Sri Venkateshwara Medical College Hospital \& \\ Research Centre, Puducherry, India, ${ }^{2}$ Dr. Shanmuga Arumugasamy S, Assistant Professor, ${ }^{3}$ Dr. Manikandasamy V, \\ Assistant Professor, ${ }^{4}$ Dr. Shafna Azeez, Junior Resident, ${ }^{5}$ Dr. Hemalathaa K, Junior Resident, all authors are affiliated \\ with Department of Paediatrics, Velammal Medical College, Madurai, India
}

Address for Correspondence: No 504, Doctors Quarters, Sri Venkateshwara Medical College Hospital \& research centre, Ariyur, Puducherry-Villupuram Main Road, Puducherry - 605102, India. Email id: maheswarijipmer@gmail.com

\begin{abstract}
Objectives: This study was undertaken to know about the magnitude, clinical spectrum and etiology of liver diseases in children in a tertiary care teaching hospital. Materials and Methods: This is a hospital based, retrospective, descriptive study. It was done on 45 children with hepatobiliary diseases admitted to pediatric department of Velammal Medical College, Madurai from Jan 2016 - Dec 2016. Results: As about 45 children out of 2259 pediatric admissions, had hepatobiliary disorders. This was contributing to $1.99 \%$ of total admissions. Liver function test was deranged in (73.3\%) of children. Males (62.2\%), outnumbered, females (37.7\%) in our study. Children less than 5 years of age were most commonly affected $(46.6 \%)$. Most common symptom in children with hepatobiliary disorders were jaundice $(51.1 \%)$, nausea/vomiting (46.6\%), anorexia (40\%), pain abdomen (33.3\%), high coloured urine (28.8\%), bleeding manifestations and abdomen distension in $(20 \%)$ each, fever in (17.7\%), failure to thrive and irritability in (15.5\%) each. The most common sign observed was icterus $(51.1 \%)$, hepatomegaly $(42.2 \%)$. Ascitis and splenomegaly was noted in (26.6\%) each, edema in (20\%) and pallor in (15.5\%) of children. Acute liver diseases were more common (68.8\%) than chronic liver diseases $(31.1 \%)$. The most common etiology of acute liver disease was acute viral hepatitis (28.8\%), cholelithiasis (22.2\%), non-alcoholic fatty liver disease (6.6\%), liver abscess (4.4\%), acute viral hepatitis with acalculous cholecystitis in $(4.4 \%)$, acute liver failure due to paracetamol poisoning in $(2.2 \%)$ of children. Etiology noted for chronic liver diseases were biliary atresia (13.3\%), idiopathic cirrhosis and wilsons disease in (6.6\%) each, autoimmune hepatitis and chronic hepatitis in $(2.2 \%)$ each. Conclusion: Since age is the single most important determinant in successful management of biliary atresia, recognition and definitive identification of the condition as the cause of neonatal cholestasis syndrome in a given case very early after the onset of symptoms is of paramount importance.
\end{abstract}

Keywords: Children, Hepatobiliary disorders, Biliary atresia, Cirrhosis.

\section{Introduction}

Childhood liver disorders constitute a major proportion of hospital admissions in India. The outlook of hepatobiliary disorders has undergone tremendous change with advent of better diagnostic tools like ultrasound, radionuclear scan, viral and autoimmune markers, endoscopic retrograde cholangiography, digital substraction angiography and improved sectioning and staining techniques of liver tissue specimens [1]. Diseases of the liver contribute

Manuscript received: $18^{\text {th }}$ April 2017

Reviewed: $26^{\text {th }}$ April May 2017

Author Corrected: $6^{\text {th }}$ May 2017

Accepted for Publication: $15^{\text {th }}$ May 2017 significantly to childhood morbidity and mortality. The clinical features of liver dysfunction may include symptoms related to digestion problems such as abnormal fat absorption and metabolism, coagulopathies, blood sugar abnormalities and immune disorders. Others include features of cholestasis, portal hypertension and esophageal varices [2]. Liver diseases among children include a broad spectrum of disorders such as infections, developmental abnormalities and metabolic disorders that finally result in hepatic dysfunction and cirrhosis. Acute and chronic liver diseases constitute the majority of liver disorders among 
children. Whereas hepatitis A and E are the common causes of acute liver disease in developing and under developed countries, metabolic causes predominate in developed countries. Certain biliary disorders such as biliary atresia present as chronic liver diseases in regions where diagnosis is delayed beyond twelve weeks. Such children often present with cirrhosis and portal hypertension [3]. Recent studies suggest that nonalcoholic fatty liver disease is an increasingly recognized condition during childhood, especially in overweight and obese children [4]. The hepatic injury in Wilsons disease is believed to be caused by excess copper, which acts as a pro oxidant and promotes the generation of free radicals [5]. The common causes for chronic liver disease in children are hepatitis B, hepatitis C, hepatitis D, autoimmune hepatitis and metabolic disorders like Wilsons disease and alpha 1 antitrypsin deficiency. In majority the etiology remains uncertain [6]. In infants, cirrhosis is most often caused by biliary atresia and genetic-metabolic disorders, while in older children, it tends to result from autoimmune hepatitis, Wilsons disease, alpha-1-antitrypsin deficiency and primary sclerosing cholangitis [7]. The need for accurate diagnosis of biliary atresia soon after clinical manifestations is important as response to surgical results will be best if the operation is performed around 8 weeks of age [8]. Diagnosis of Wilsons disease with hepatic presentation in childhood using clinical and laboratory parameters is still challenging and is often missed or delayed. Hepatic involvement is prominent during childhood and mimics the features of a variety of acute and chronic liver diseases $[9,10]$.

\section{Materials and Methods}

Study design: Retrospective, descriptive study.
Setting: Hospital based study in a tertiary care centre in south India.

Inclusion criteria:

* 3months to 15 years old children presenting to the pediatric department with liver disease

* Complete patient information along with the investigation reports in the medical records.

\section{Exclusion Criteria:}

*Children less than 3 months and more than 15 years of age

*Medical records with incomplete information/ Evaluation done in other hospitals.

Participants: Children aged 3 months to 15 years of age admitted and treated in pediatric department from January 2016-December 2016 in a tertiary care centre, south India.

Variables: magnitude, clinical spectrum, etiology.

Data source: The hospital records of the children with hepatobiliary diseases were retrieved from the medical records department following due permission.

\section{Study size: 45 children \\ Quantitative variable: magnitude \\ Statistical analysis: Simple proportion test}

The following data was collected from the medical records department (MRD) about the children included in this study.

*Age, sex, symptoms and signs of hepatobiliary diseases.

*Results of liver function tests, coagulogram, viral serology markers, autoimmune antibodies, serum ceruloplasmin, urinary copper levels, abdominal ultrasound, upper GI endoscopy findings, liver biopsy, and HIDA scan report was noted.

\section{Results}

Out of 2259 children, admitted in pediatric ward from Jan 2016- Dec 2016, about 45 children had hepatobiliary disorders, contributing to $1.99 \%$ of the total number of admissions. Liver function tests were deranged in 33 out of 45 children (73.3\%). The analysis of 45 children who fulfilled the inclusion criteria is as below.

Table-1: Distribution of children according to demographic data.

\begin{tabular}{|c|c|c|}
\hline Demographic data & Number & Percentage \\
\hline Gender & 28 & 62.2 \\
Male & 17 & 37.7 \\
Female & 21 & 46.6 \\
Age group & 9 & 20 \\
3 months -5 years & 15 & 33.3 \\
6-10 years & & \\
11-15 years & & \\
\hline
\end{tabular}


According to table 1- it was seen that males 28(62.2\%), outnumbered female children. Hepatobiliary disorders was most commonly seen in children less than 5 years of age 21 (46\%), followed by, children of 11-15 years of age 15 (33.3\%) and 6-10 years of age $9(20 \%)$.

Table-2: Distribution of children according to clinical profile of hepatobiliary disorders.

\begin{tabular}{|c|c|c|}
\hline Clinical profile & No. & Percentage \\
\hline Symptoms & 23 & 51.1 \\
Jaundice & 21 & 46.6 \\
Nausea/vomiting & 18 & 40.0 \\
Anorexia & 15 & 33.3 \\
Pain-abdomen & 13 & 28.8 \\
High-coloured-urine & 9 & 20 \\
Hematemesis/melena & 9 & 20 \\
Abdomen-distension & 8 & 17.7 \\
Fever & 7 & 15.5 \\
Failure-to-thrive & 7 & 15.5 \\
Irritability & 4 & 8.8 \\
Clay coloured stools & 3 & 6.6 \\
Obesity & 2 & 4.4 \\
Itching & & \\
Signs & 23 & 51.1 \\
Icterus & 19 & 42.2 \\
Hepatomegaly & 12 & 26.6 \\
Ascitis & 12 & 26.6 \\
Splenomegaly & 9 & 20.0 \\
Edema & 7 & 15.5 \\
Pallor & & \\
\hline
\end{tabular}

According to table -2, it was observed that, most common symptom in children with hepatobiliary disorders were, jaundice $23(51.1 \%)$, nausea/vomiting 21(46.6\%), anorexia in $18(40 \%)$. This was followed by pain abdomen in 15 (33.3\%), high coloured urine in 13 (28.8\%), bleeding manifestations and abdomen distension in 9 children each (20\%), fever in $8(17.7 \%)$, failure to thrive and irritability in 7 children each (15.5\%). The most common sign observed was icterus in $23(51.1 \%)$, hepatomegaly 19 (42.2\%). Ascitis and splenomegaly was noted in 12 children each (26.6\%).

Table -3: Distribution of children according to etiology of hepatobiliary disorders.

\begin{tabular}{|c|c|c|}
\hline Etiology & No. & Percentage \\
\hline Acute liver diseases & & 28.8 \\
Acute-viral-hepatitis(AVH) & 13 & 22.2 \\
Cholelithiasis & 10 & 6.6 \\
Non-alcoholic fatty liver disease & 3 & 4.4 \\
Liver-abscess & 2 & 4.4 \\
AVH with acalculous cholecystitis & 2 & 2.2 \\
Acute liver failure (Paracetamol poisoning) & 1 & $\mathbf{6 8 . 8}$ \\
Total & $\mathbf{3 1}$ & 6.6 \\
Chronic liver diseases & & 6.6 \\
Biliary atresia & 6 & 2.2 \\
Idiopathic Cirrhosis & 3 & 2.2 \\
Wilsons disease & 3 & $\mathbf{3 1 . 1}$ \\
\hline Autoimmune hepatitis & 1 & 1 \\
\hline Chronic hepatitis & $\mathbf{1 4}$ & \\
\hline
\end{tabular}


According to table -3 , it was seen that, acute liver diseases $31(68.8 \%)$ were more common than chronic liver diseases 14 (31.1\%). Among children affected with ALD, the most common etiology was acute viral hepatitis in $13(28.8 \%)$, cholelithiasis in $10(22.2 \%)$, NAFLD in $3(6.6 \%)$. This was followed by liver abscess in $2(4.4 \%)$, AVH with acalculous cholecystitis in $2(4.4 \%)$, acute liver failure due to paracetamol poisoning in 1(2.2\%) of children.

Among children affected with chronic liver diseases, the most common etiology was biliary atresia in $6(13.3 \%)$ of children. All 6 children presented after 3 months of age, out of which two them had under gone kasai procedure, but died of end stage liver disease at later date. Other etiology of chronic liver disease was idiopathic cirrhosis in 3(6.6\%), Wilsons disease in 3 (6.6\%), autoimmune hepatitis in 1 (2.2\%) and chronic hepatitis in 1 (2.2\%) of children.

\section{Discussion}

In our study it was seen, that males outnumbered female children in hepatobiliary disorders. Similar results were reported by various authors $[11,12]$. The most common age group affected in our study was children less than 5 years of age. This is in accordance to studies done by authors in Middle East [11,13].

The most common symptom noted in our study was jaundice $(51.6 \%)$, nausea/vomiting $(46.6 \%)$, followed by anorexia (40\%) and pain abdomen $(33.3 \%)$. The most common sign noted was icterus (51.1\%), hepatomegaly (42\%), followed by ascitis and splenomegaly (26.6\%) each. Similarly, a study done in Nigeria has shown jaundice $(71.4 \%)$, abdomen pain $(40.5 \%)$ as the most common symptoms and jaundice $(71.4 \%)$, hepatomegaly $(38.1 \%)$, splenomegaly $(19 \%)$ as the most common signs[2].

It was observed in our study that ALD (68.8\%) was more common than CLD (31.1\%). But in contrast to our results, a study done by Indian author has revealed that, CLD (36\%) being more common than ALD (28\%) and NCS $(26 \%)$ in children [14]. The most common cause of ALD in our study was acute viral hepatitis in (28.8\%) of children. This in accordance to a study done by Indian author, who revealed AVH (43\%) as the most common cause for ALD[3]. There was (2.2\%) of children with acute liver failure due to paracetamol poisoning in our study.

Similarly a western study has revealed paracetamol poisoning to be the most common cause of acute liver failure in children [15]. Our study noted that, the incidence of NAFLD was $3(6.6 \%)$. This is in accordance to a study done by Indian author who noted 7 out of 128 children (5.4\%) with NAFLD who underwent liver biopsy [16].

The most common etiology of CLD observed in our study was biliary atresia (13.3\%). Other etiologies noted for CLD were idiopathic cirrhosis $(6.6 \%)$, Wilsons disease $(6.6 \%)$, followed by autoimmune hepatitis and chronic hepatitis in $(2.2 \%)$ each. A study done by Indian author has noted the etiology of CLD being Wilsons disease in $(21 \%)$, autoimmune hepatitis in (4\%) of children [1]. A study done in kashmir has revealed idiopathic cirrhosis (52\%), as the most common cause of CLD [3]. Similar to our study, various studies done in South Africa and Omani children, has revealed biliary atresia as one of the most common cause of CLD in children [17,18].

\section{Conclusion}

Since age is the single most important determinant in successful management of biliary atresia, recognition and definitive identification of the condition as the cause of NCS in a given case very early after the onset of symptoms is of paramount importance.

Acknowledgement: I thank all the MRD staffs, for helping me in collection of patient information from medical records for this study.

\section{Abbreviation}

AVH- acute viral hepatitis, ALD- acute liver diseases, CLD- chronic liver diseases, NCS- neonatal cholestasis syndrome, MRD - medical records department, NAFLD- non- alcoholic fatty liver disease, HIDA Scanhepatobiliary iminodiacetic acid scan.

Funding: Nil, Conflict of interest: None initiated, Perission from IRB: Yes

\section{References}

1. Yachha SK, Sharma BC, Khanduri A, Srivastava A. Current spectrum of hepatobiliary disorders in northern India. Indian pediatr. 1997 Oct;34(10):885-890. https:// www.ncbi.nlm.gov/pubmed/9567550

2. Ahamed PA, Ulonnam CC, Mohammed-Nafiu R, Ballong J, Nwankwo G. Pattern of liver diseases among 
children attending the National Hospital Abuja, Nigeria. Niger J Paed 2016;43(1):46-50.

3. Dar GA, Zarger SA, Jan K, Malik MI, Mir TA, Dar MA. Spectrum of Liver diseases among children in kashmir valley. Academic medical journal of India. 2014 Nov 20;2(3):80-86.

4. Wieckowska A, Feldstein AE. Nonalcoholic fatty liver disease in the pediatric population: a review. Curr Opin Pediatr. 2005 Oct;17(5):636-41.

5. Tahir A, Malik FA, Ahmad I, Krishin J, Akhtar P. Aetiological factors of chronic liver disease in children. J Ayub Med Coll Abbottabad 2011; 23 (2) :12-14. https: //www. ayubmed.edu.pk/JAMC/23-2/ Awais.pdf

6. Hanif M, Raza J, Qureshi H, Issani Z. Etiology of chronic liver disease in children. J Pak Med Assoc. 2004 Mar;54(3):119-22.

7. Pinto RB, Schneider AC, da Silveira TR. Cirrhosis in children and adolescents: An overview. World J Hepatol. 2015 Mar 27;7(3):392-405. doi: 10.4254/ wjh.v7.i3.392.

8. Nayak NC, Vasdev N. Neonatal cholestasis syndrome: identifying the disease from liver biopsy. Indian Pediatr. 2002 May;39(5):421-5.

9. Karim MB, Rahman MM, Islam MS. Wilsons disease with hepatic presentation in childhood. Mymensingh Med J. 2007 Jan;16(1):29-32.

10. Yuce A, Kocak N, Gurakan F, Ozen H. Wilsons disease with hepatic presentation in childhood. Indian Pediatr. 2000 Jan;37:31-36.
11. Sabir OM. Pathologic causes of liver disease in Sudanese children: Results of 450 liver needle biopsies at a single children hospital. Sudan J Paediatr. 2011; 11(1):38-41.

12. Dhole SD, Kher AS, Ghildiyal RG, Tambse MP. Chronic Liver Diseases in Children: Clinical profile and Histology. Journal of Clinical and Diagnostic Research. JCDR. 2015;9(7):SC04-SC07.

13. Monajemzadeh M, Tabriz HM, Mahjoub F, Fallahi G, Farahmand F. Liver needle biopsy in Iranian pediatric patients: diagnostic significance and pattern of liver diseases. Indian J Pathol Microbiol. 2009 Jan-Mar; 52 (1):10-3.

14. Dangwal TR, Aggarwal V, Malhotra V, Baveja U, Mittal SK. Clinical spectrum of chronic liver disease in north Indian children. Trop Gastroenterol. 1997 OctDec; 18(4):174-6.

15. Williams R. Classification, etiology, and considerations of outcome in acute liver failure. Semin Liver Dis. 1996 Nov;16(4):343-8.

16. Ramakrishna B, Date A, Kirubakaran C, Raghupathy $\mathrm{P}$. The pattern of liver disease in Indian children: a review of 128 biopsied cases. Ann Trop Paediatr. 1993;13(2):159-63.

17. Muthuphei MN. Childhood liver diseases in GaRankuwa Hospital, South Africa. East Afr Med J. 2000 Sep;77(9):508-9.

18. Akinbami FO, Venugopalan, Nirmala V, Suresh J, Abiodun P. Pattern of chronic liver disease in Omani children- a clinicopathological review. West Afr J Med.2004 Apr-Jun;23(2):162-6.

\section{How to cite this article?}

Maheswari K, Shanmuga Arumugasamy S, Manikandasamy V, Shafna azeez, Hemalathaa K. Magnitude, clinical spectrum and etiology of hepatobiliary disorders in children- a tertiary care experience. J PediatrRes.2017;4(05):310314.doi:10. 17511/ijpr.2017.i05.04 